\title{
Release of cytochrome $c$ and activation of pro-caspase-9 following lysosomal photodamage involves bid cleavage
}

\author{
JJ Reiners Jr ${ }^{\star, 1}$, JA Caruso ${ }^{1}$, P Mathieu', B Chelladurai ${ }^{1}$, \\ X-M Yin ${ }^{2}$ and D Kessel ${ }^{3,4}$ \\ ${ }^{1}$ Institute of Environmental Health Sciences, Wayne State University, Detroit, \\ MI 48201, USA \\ 2 Department of Pathology, University of Pittsburgh School of Medicine, \\ Pittsburgh, PA 15261, USA \\ ${ }^{3}$ Department of Pharmacology, Wayne State University School of Medicine, \\ Detroit, MI 48201, USA \\ 4 Department of Medicine, Wayne State University School of Medicine, Detroit, \\ MI 48201, USA \\ * Corresponding author: JJ Reiners Jr, Institute of Environmental Health \\ Sciences, Wayne State University, 2727 Second Ave., Rm 4000, Detroit, \\ MI 48201, USA. Tel: (313) 963-7661; Fax: (313) 577-0082; \\ E-mail: john.reiners.jr@wayne.edu
}

Received 18.12.01; revised 25.1.02; accepted 11.2.02

Edited by T Ferguson

\begin{abstract}
Photodynamic therapy (PDT) protocols employing lysosomal sensitizers induce apoptosis via a mechanism that causes cytochrome crelease prior to loss of mitochondrial membrane potential $\left(\Delta \Psi_{m}\right)$. The current study was designed to determine how lysosomal photodamage initiates mitochondrialmediated apoptosis in murine hepatoma 1c1c7 cells. Fluorescence microscopy demonstrated that the photosensitizer $\mathrm{N}$-aspartyl chlorin e6 (NPe6) localized to the lysosomes. Irradiation of cultures preloaded with NPe6 induced the rapid destruction of lysosomes, and subsequent cleavage/activation of Bid, pro-caspases-9 and -3. Pro-caspase-8 was not activated. Release of cytochrome coccurred at about the time of Bid cleavage and preceded the loss of $\Delta \Psi_{\mathrm{m}}$. Extracts of purified lysosomes catalyzed the in vitro cleavage of cytosolic Bid, but not pro-caspase-3 activation. Pharmacological inhibition of cathepsin $B, L$ and $D$ activities did not suppress Bid cleavage or pro-caspases- 9 and -3 activation. These studies demonstrate that photodamaged lysosomes trigger the mitochondrial apoptotic pathway by releasing proteases that activate Bid.

Cell Death and Differentiation (2002) 9, 934-944. doi:10.1038/ sj.cdd. 4401048
\end{abstract}

Keywords: apoptosis; Bid; lysosomes; NPe6; photodynamic therapy (PDT)

Abbreviations: AFC, 7-amino-4-(trifluoromethyl)coumarin; AMC, 7-amino-4-methylcoumarin; $\mathrm{AO}$, acridine orange; $\mathrm{CPO}$, 9-capronyloxy-tetrakis(methoxyethyl) porphycene; Ac-IETD-AFC, N-acetylIle-Glu-Thr-Asp-aminofluorocoumarin; Ac-DEVD-AMC, N-acetylAsp-Glu-Val-Asp-aminomethylcoumarin; HPPH, hexyl pheophor- bide; HO342, Hoechst dye HO33342; LTB, LysoTracker Blue; LuTex, lutetium texaphyrin; NPe6, N-aspartyl chlorin e6; Pc 4, phthalocyanine; PDT, photodynamic therapy; $\Delta \Psi_{\mathrm{m}}$, mitochondrial membrane potential; tBid, truncated Bid; TMRM, tetramethylrhodamine methyl ester; Z-FA-FMK, Z-Phe-Ala-fluoromethyl ketone

\section{Introduction}

PDT is a procedure that employs light to activate photosensitizers and generate singlet oxygen. It is used to eradicate tumors, and in the treatment of atherosclerotic plaque and macular degeneration. ${ }^{1}$ It was originally assumed that PDT caused necrotic cell death. However, in 1991 Agarwal et al. ${ }^{2}$ showed that apoptosis could also occur. Subsequent studies demonstrated PDT-mediated apoptotic/ necrotic outcomes in various cell types, ${ }^{1,3}$ with the mode of cell death being influenced by cell type, identity and concentration of photosensitizer, and light doses used in the PDT protocol. ${ }^{3}$

A variety of agents function as photosensitizers in PDT protocols. However, the initial intracellular target of photosensitizers is agent specific. ${ }^{1,3,4}$ For example, the photosensitizers LuTex and NPe6 cause an almost immediate disruption of the lysosomes upon irradiation. ${ }^{1,3-6}$ In contrast, irradiation of cells preloaded with the photsensitizers CPO, HPPH and Pc 4 has no effect on lysosomes. Instead, one sees a rapid loss of $\Delta \Psi_{m}$ and release of cytochrome $c^{1,3,7-9}$ These effects most likely reflect: (a) the sites of sensitizer accumulation ${ }^{6,10,11}$ because the reactive oxygen species formed upon irradiation have a limited ability to migrate from the site(s) of formation; ${ }^{12}$ and (b) the unique ability of some photosensitizers to photo oxidize and cleave Bcl-2 upon excitation. ${ }^{13,14}$

Irradiation of cells preloaded with lysosomal photosensitizers eventually causes the release of cytochrome $c$ and the activation of pro-caspase- $3 .^{5,8}$ The mechanisms by which lysosomal sensitizers cause these effects are not known. However, one can envision several possibilities. For example, several investigators have reported that extracts of purified lysosomes can directly activate pro-caspases in vitro. ${ }^{15-18}$ Alternatively, released lysosomal proteases may directly attack the mitochondria causing damage sufficient to facilitate the release of cytochrome $c$. Cytosolic cytochrome $c$ could then activate pro-caspase-3 via Apaf1/caspase-9. Released lysosomal proteases may also activate pro-apoptotic cytosolic proteins capable of triggering cytochrome $c$ release. Indeed, Stoka et al. ${ }^{19}$ recently demonstrated that lysosomes contain a proteolytic activity capable of the in vitro conversion of Bid to tBid, a proapoptotic member of the $\mathrm{BCl}-2$ supergene family. ${ }^{20,21} \mathrm{tBid}$, like the pro-apoptotic protein Bax, can trigger the release of cytochrome $c$ from isolated mitochondria. ${ }^{22-24}$ It is currently thought that tBid induces the intra-membranous 
oligomerization of the pro-apoptotic protein Bak into a pore that facilitates the release of cytochrome $c .^{25-27}$ The cytochrome $c$ release catalyzed by tBid occurs in the absence of a loss of $\Delta \Psi_{\mathrm{m}}$, and cannot be suppressed by cyclosporin A or bongkrekic acid, inhibitors of mitochondrial permeability transition. ${ }^{22-24}$

We previously reported that irradiation of murine hepatoma 1c1c7 cultures preloaded with NPe6 caused lysosomal disruption, dispersion of lysosomal proteases throughout the cytosol, and apoptosis. ${ }^{5}$ In the current study we determined if Bid activation occurs in this PDT protocol. Our studies demonstrate that Bid cleavage does occur and precedes/accompanies the initiation of cytochrome $c$ release and activation of the Apaf-1/pro-caspase- 9 pathway. Cytochrome $c$ release occurred prior to the loss of $\Delta \Psi_{\mathrm{m}}$. Furthermore, we demonstrate that extracts of purified lysosomes can convert cytosolic Bid to tBid, but can not directly activate pro-caspase-3.

\section{Results \\ Localization of NPe6 to lysosomes}

1c1c7 cultures preloaded with NPe6 exhibited punctate, perinuclear fluorescence when excited (Figure 1A). In order to determine if the staining pattern represented lysosomes we attempted to colocalize NPe6 staining with LTB fluorescence. LTB is an acidophilic dye commonly used to localize lysosomes and endosomes. LTB also exhibited a punctate, perinuclear staining pattern in 1c1c7 cultures (Figure 1B). The merged stained images revealed that NPe6 colocalized to a subset of the LTB-stained structures (Figure 1C).

\section{Cell killing and activation of pro-caspase-3 by NPe6 in PDT protocols}

Exposure to either 22 or $66 \mu \mathrm{M} \mathrm{NPe} 6$ for $1 \mathrm{~h}$, in the absence of light, was not cytotoxic to 1c1c7 cultures (time 0 in Figure 2A). Similarly, in the absence of photosensitizer, cell viability was unaffected by $140 \mathrm{~s}$ of irradiation $\left(210 \mathrm{~mJ} / \mathrm{cm}^{2}\right.$, Figure 2A). However, irradiation of cultures preloaded with either 22 or $66 \mu \mathrm{M}$ NPe6 resulted in light-dose-dependent, and sensitizerconcentration-dependent cell killing (Figure $2 A$ ). The $L D_{50 s}$ for 22 and $66 \mu \mathrm{M} \mathrm{NPe} 6$ were $\sim 165 \mathrm{~mJ} / \mathrm{cm}^{2}$ (110 s of irradiation) and $37.5 \mathrm{~mJ} / \mathrm{cm}^{2}$ (25 s of irradiation), respectively.

Reductions in viability, as scored in colony formation assays, were also paralleled by the activation of procaspase-3 (Figure 2B,C). Neither irradiation alone, nor NPe6 alone, activated pro-caspase-3. However, when used in combination, pro-caspase-3 activation occurred in a lightdose-dependent, and sensitizer-concentration-dependent fashion (Figure 2B,C). Caspase-3 activities were elevated slightly within $2 \mathrm{~h}$ of irradiation of sensitized cultures, and generally peaked within an additional 3-5 h (Figure 2B,C). Maximum increases of $\sim 200$-fold were measured in cultures treated with $66 \mu \mathrm{M} N$ Ne6 and $\geqslant 90 \mathrm{~mJ} / \mathrm{cm}^{2}$ ( $\geqslant 60 \mathrm{~s}$ of irradiation). Light microscopy revealed that most cells in cultures sensitized with $66 \mu \mathrm{M}$ NPe6 were undergoing apoptosis within $6 \mathrm{~h}$ of irradiation with $135 \mathrm{~mJ} / \mathrm{cm}^{2}$ (90 s of irradiation). In subsequent PDT studies, unless
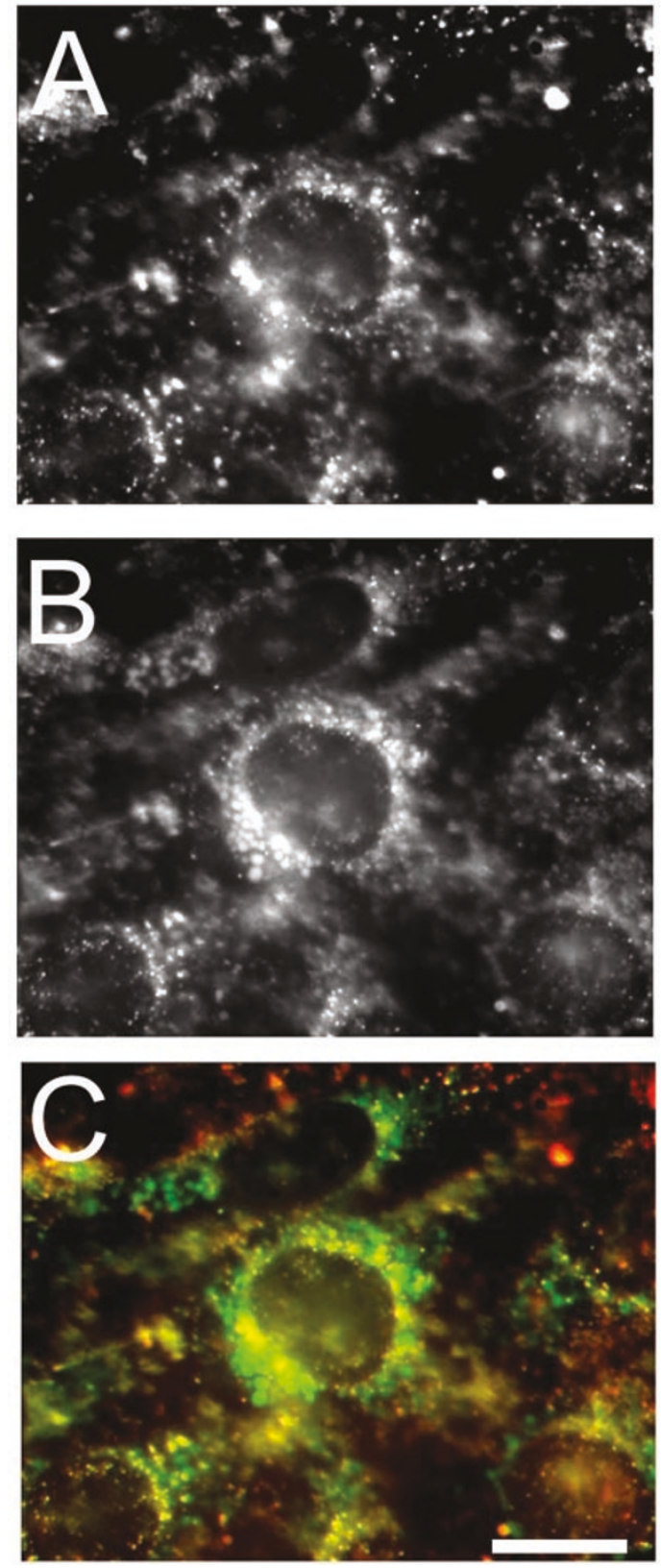

Figure 1 Localization of NPe6 in 1c1c7 cells. Cells grown on coverslips were preloaded with $66 \mu \mathrm{M} N P e 6$ for 30 min prior to being washed, refed and loaded with LysoTracker Blue (LTB). After 10 min the cultures were washed with PBS and analyzed by fluorescence microscopy. Panels represent fluorescence of: (A) NPe6, (B) LTB, (C) merged image of NPe6+LTB. Bar represents 20 microns

stated otherwise, cultures were treated with $66 \mu \mathrm{M}$ NPe6 and $135 \mathrm{~mJ} / \mathrm{cm}^{2}$.

\section{PDT induction of apoptosis}

AO stained lysosomes in non-treated, control cultures exhibited a punctate pattern (Figure 3). Irradiation of cultures preloaded with NPe6 almost completely abolished AO staining. This effect was observed within $1 \mathrm{~h}$ of irradiation. 

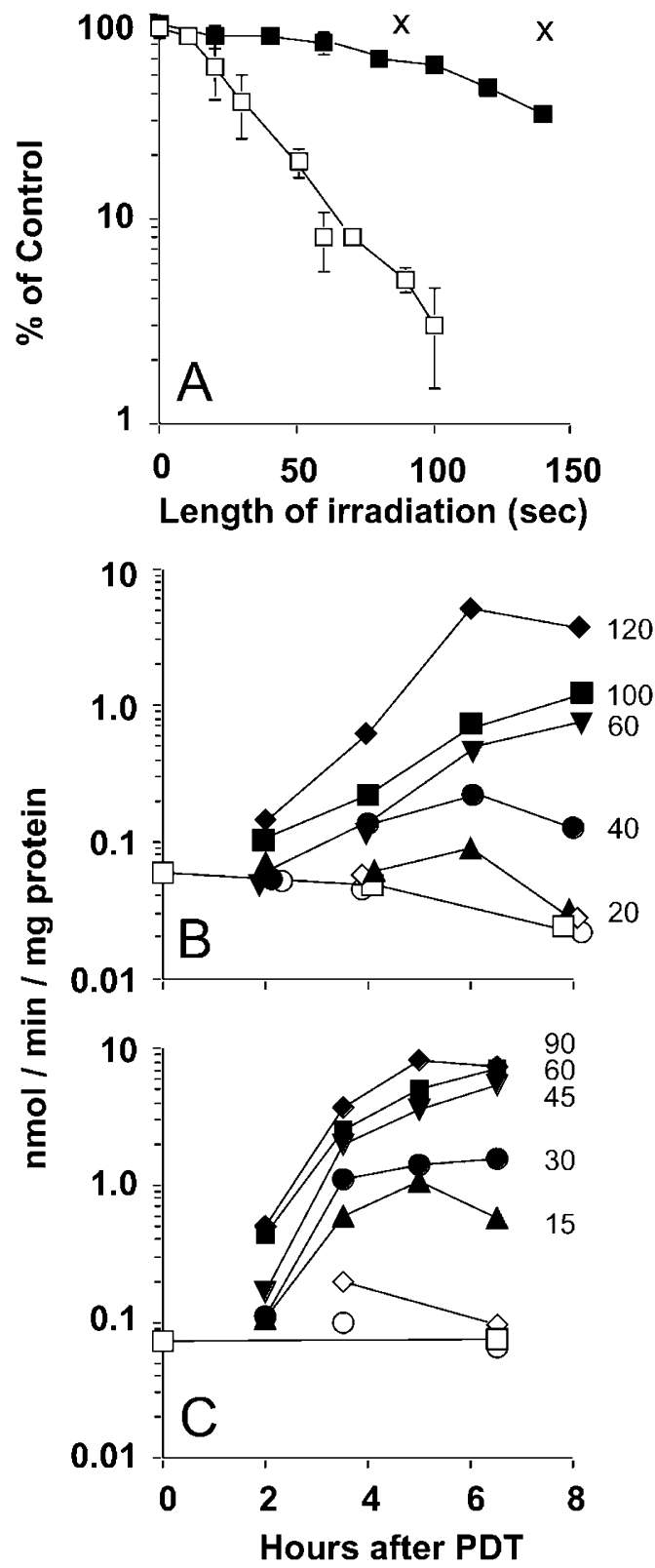

Figure 2 Light dose and NPe6-concentration-dependent killing and activation of caspase-3 in PDT protocols. (A) 1c1c7 cells were plated at densities of $400-800$ cells $/ 60 \mathrm{~mm}$ dish. Approximately $16 \mathrm{~h}$ later cultures were loaded with $22 \mu \mathrm{M}(\square)$ or $66 \mu \mathrm{M}(\square) \mathrm{NPe} 6$ for $45 \mathrm{~min}$ prior to being washed refed and irradiated for the indicated period of time. Other cultures were only irradiated $(X)$. Colonies were counted 7-9 days after irradiation. Data represent means \pm S.D. of 3-4 plates. (B) Subconfluent, 2 day-old cultures were loaded with $22 \mu \mathrm{M} \mathrm{NPe} 6$ for 45 min prior to being washed, refed and irradiated for $20-120 \mathrm{~s}$ (time is indicated next to solid symbol). Cultures were harvested at various times after irradiation for assay of caspase-3 activities. (C) Same as B except that cultures were preloaded with $66 \mu \mathrm{M}$ NPe6. Open symbols in $\mathbf{B}$ and $\mathbf{C}$ represent: no treatment $(\square)$, light alone $(\diamond)$, and NPe6 alone $(O)$. Data in panels $B$ and $C$ represent means \pm S.D. of triplicate assays of a single culture. One $s$ of irradiation $=1.5 \mathrm{~mJ} / \mathrm{cm}^{2}$. Similar results were obtained in a second independent experiment
In contrast, AO staining was unaffected in parallel cultures that were irradiated in the absence of NPe6, or treated solely with NPe6 (data not presented).

TMRM is a fluorescent probe used to monitor $\Delta \Psi_{\mathrm{m}}$. Nontreated, control cells stained with TMRM exhibited a perinuclear punctate pattern (Figure 3). No dramatic changes in either the pattern or the intensity of TMRM staining occurred within $4 \mathrm{~h}$ of irradiation of NPe6sensitized cultures (Figure 3). However, TMRM staining intensity decreased dramatically within $5 \mathrm{~h}$ of PDT (Figure 3), and was almost uniformly absent within $6 \mathrm{~h}$ of PDT (data not presented).

Analyses of morphology and nuclear condensation (Figure 3 ) indicated that some of the cells in irradiated $1 \mathrm{c} 1 \mathrm{c} 7$ cultures preloaded with NPe6 were undergoing apoptosis within $4 \mathrm{~h}$ of irradiation. By $6 \mathrm{~h}$ a large percentage of the cells had detached, all of which where apoptotic. Of the remaining attached cells, most exhibited nuclear condensation.

The conversion of cytosolic Bid to tBid occurred within $3 \mathrm{~h}$ of PDT (Figure 4A). Analyses employing ECL exposure times different than those used to generate the data depicted in Figure 4 clearly demonstrated that the appearance of tBid was accompanied by the disappearance of Bid (data not presented). Cytosolic cytochrome $c$ contents were elevated within $3 \mathrm{~h}$ of PDT and continued to increase with time (Figure 4A). The appearance of cytochrome $c$ was paralleled by the cleavage/activation of pro-caspase-9 (Figure 4A). Significant increases in caspase-3 activity occurred only after the activation and appearance of caspase-9 (Figure 4B). Specifically, in the study reported in Figure 4, caspase-3 activity was unaffected for the first $2 \mathrm{~h}$ after PDT. However, within 3 and $4 \mathrm{~h}$ of PDT caspase-3 activities were $\sim 7$ and 20 -fold higher than the activities measured in non-treated cultures, respectively. Thereafter, caspase-3 activity continued to increase. Neither irradiation alone, nor exposure to only NPe6, activated pro-caspase-3 (Figure 4B).

Peng et al. ${ }^{28}$ demonstrated that PDT sensitizers sequestered in organelles can be released into the cytoplasm following irradiation under some circumstances, and undergo subsequent photoactivation in the cytoplasm if sufficient light is present. Furthermore, recent studies demonstrate that several mitochondrial sensitizers, which are normally photoactivated in the cytoplasm of the cell, cause photocleavage of $\mathrm{Bcl}-2$ in PDT protocols. ${ }^{13,14}$ Cultures were irradiated for $90 \mathrm{~s}$ in the studies presented in Figure 4 ( $\left(\mathrm{LD}_{98}\right.$ conditions). At issue is whether the Bid cleavage seen in Figure 4 reflects the actions of a released lysosomal protease, or photocleavage mediated by NPe6 that is released from the lysosome and subsequently activated in the cytosol. To address this issue we repeated the studies presented in Figure 4, but shortened the irradiation time to $45 \mathrm{~s}$ ( $\left(\mathrm{LD}_{75}\right.$ conditions). Irradiation for $45 \mathrm{~s}$ also resulted in Bid cleavage, and pro-caspases-9 and -3 activation (Figure 5A). tBid and processed caspase-9 were clearly present within $4 \mathrm{~h}$ of irradiation. Caspase-3 activities were also significantly elevated $(\sim 70$-fold) within $4 \mathrm{~h}$ of irradiation. By employing shorter ECL exposure times it was possible to demonstrate a time-dependent loss of Bid 


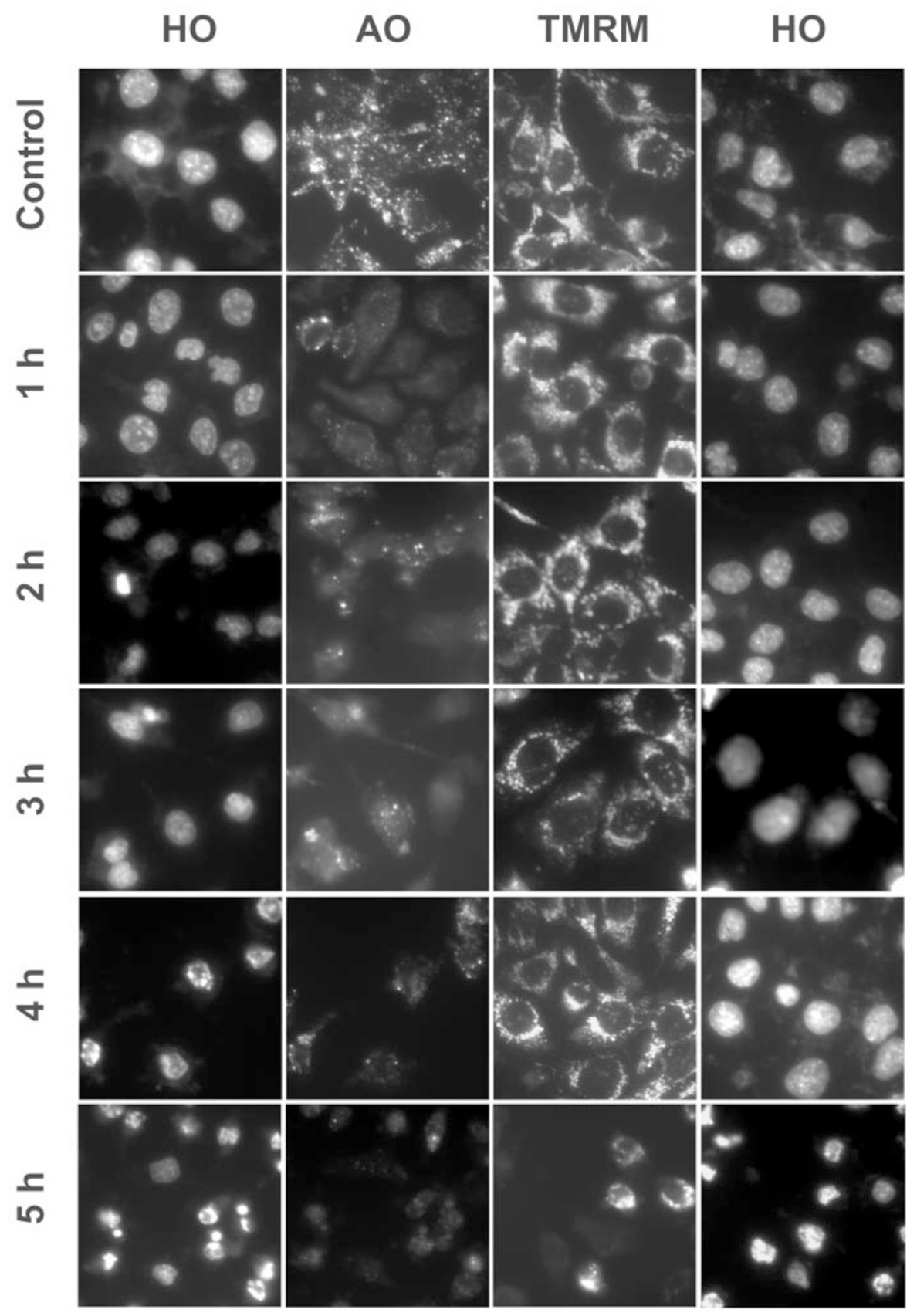

Figure 3 Effects of PDT with NPe6 on lysosomal integrity and mitochondrial membrane potential. Cells grown on coverslips were preloaded with $66 \mu \mathrm{M}$ NPe6 for $30 \mathrm{~min}$ prior to being washed, refed and irradiated $\left(135 \mathrm{~mJ} / \mathrm{cm}^{2}\right)$. PDT-treated cultures were co-stained at the indicated times after irradiation with either $\mathrm{HO}+\mathrm{AO}$ (first and second columns), or TMRM+HO (third and fourth columns) to visualize nuclei+lysosomes and $\Delta \Psi_{\mathrm{m}}+$ nuclei, respectively. Non-treated control cultures were treated and processed similarly. Similar results were obtained in a second independent experiment

in irradiated, NPe6-sensitized 1c1c7 cultures (Figure 5A). The Bid signal was reduced $\sim 25 \%$ and $\sim 85 \%$ within 3 and $6 \mathrm{~h}$ of irradiation, respectively.

Incubation of cytosol isolated from normal cultures with NPe 6 for $6 \mathrm{~h}$, in the absence of light, did not cause Bid cleavage and the formation of tBid (Figure 5B). Similarly, irradiation of cytosol for $90 \mathrm{~s}$, in the absence or presence of NPe6, did not stimulate Bid loss and the formation of tBid over a $6 \mathrm{~h}$ time period (Figure $5 \mathrm{~B}$ ). This resistance of Bid to $90 \mathrm{~s}$ of irradiation in vitro, in the presence of NPe6, is in marked contrast to the dramatic loss of Bid that occurred in vivo following $45 \mathrm{~s}$ of irradiation of NPe6 sensitized cultures (compare $6 \mathrm{~h}$ Bid signal in Figure $5 \mathrm{~A}$ with Bid signal in Figure $5 \mathrm{~B}$ ). Hence, the tBid formed in our PDT protocols was not the consequence of NPe6-induced Bid photocleavage. 


\section{In vitro cleavage of Bid and activation of pro-caspase- 3 by lysosomal extracts}

1c1c7 cells were broken by gentle homogenization to yield cytosol and organelle fractions. Purified cytosol was devoid of lysosomal proteins (cathepsin $\mathrm{D}$ and $\beta$-hexosaminidase) and the mitochondrial marker cytochrome $c$ (Figure $6 \mathrm{~A}$ ), but contained Bid (Figure 6B). Density gradient centrifugation of the organelle fraction yielded a lysosome preparation that contained $\beta$-hexosaminidase and mature single chain and large chain forms of cathepsin $\mathrm{D}$, but no cytochrome $c$ (Figure $6 \mathrm{~A}$ ), or Bid (Figure 6B). Incubation of the cytosolic fraction with
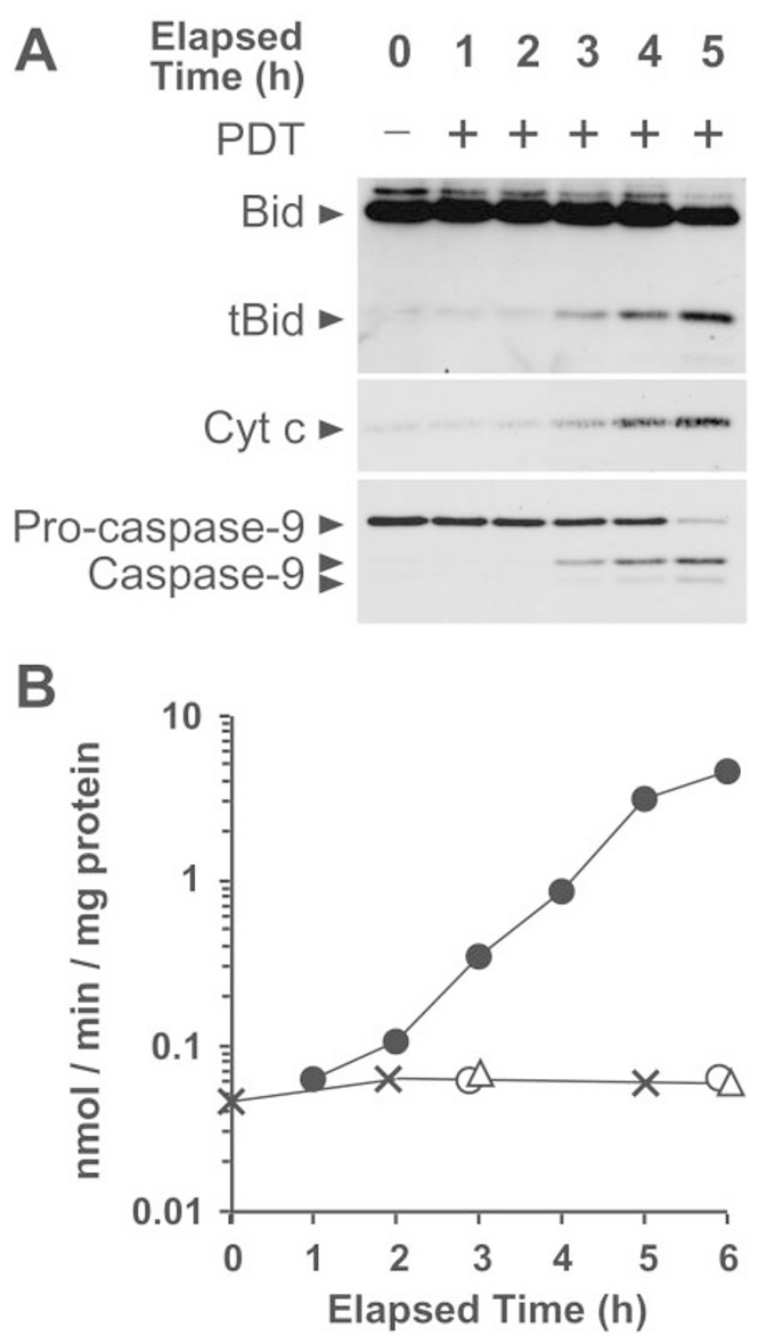

Figure 4 Kinetics of Bid cleavage, cytochrome $c$ release, and activation of pro-caspase-9 and pro-caspase-3 following high light dose irradiation of NPe6-sensitized 1c1c7 cells. Two-day-old cultures were preloaded with $66 \mu \mathrm{M}$ $\mathrm{NPe} 6$ for $45 \mathrm{~min}$ prior to being washed, refed and irradiated $\left(135 \mathrm{~mJ} / \mathrm{cm}^{2}\right)$. Cultures were harvested at various times after irradiation for analyses of: (A), Bid cleavage, cytosolic cytochrome $c$, and pro-caspase-9 cleavage; and (B), caspase-3 activity. Parallel cultures were either not treated, or only irradiated, or only sensitized with NPe6. Symbols in B are means + S.D. of triplicate assays of a single culture and represent: no treatment $(\mathrm{X})$; irradiation alone $(\triangle)$; NPe6 alone (O); and NPe6+irradiation $(\bullet)$. Western blot analyses used 20,10 , and $20 \mu \mathrm{g}$ of protein per lane for Bid, cytosolic cytochrome $c$ and caspase- 9 analyses, respectively. Similar data were obtained in a second independent study
Iysosomal extract resulted in time-dependent Bid cleavage and the formation of tBid (Figure 6B). No cleavage occurred in

A
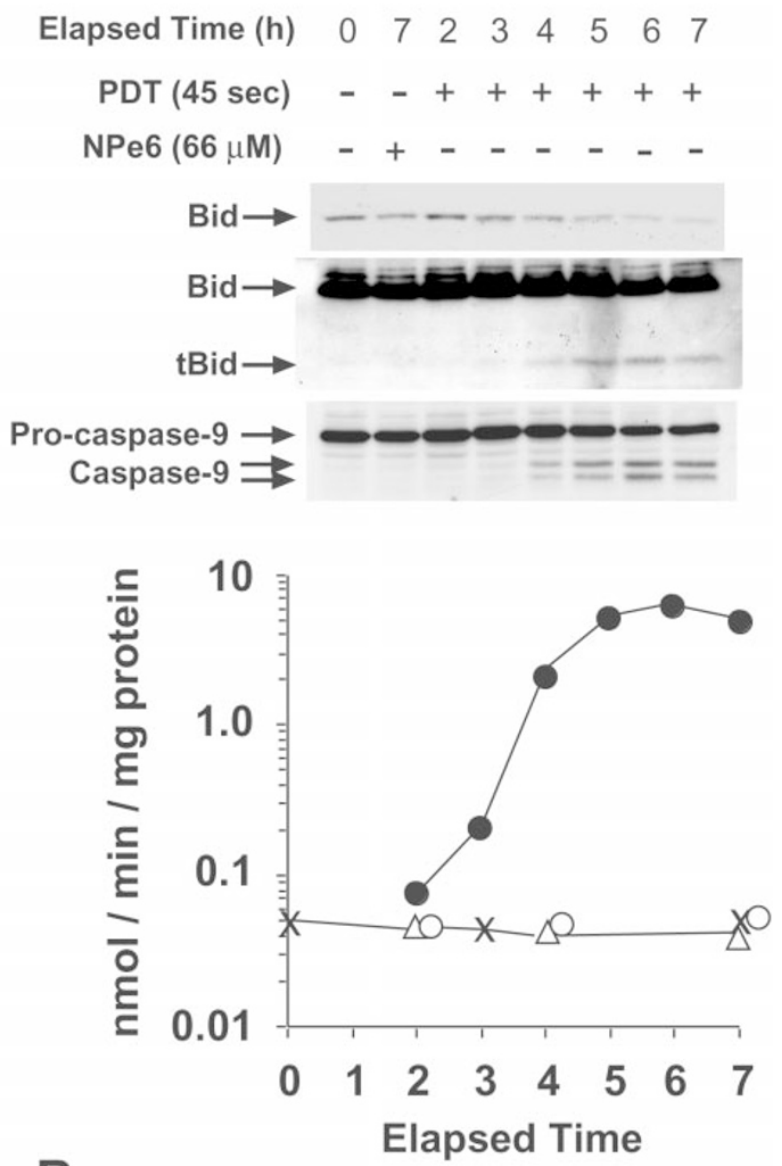

B
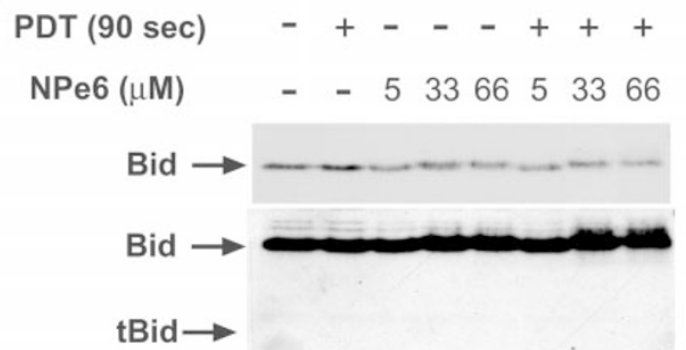

Figure 5 Kinetics of Bid cleavage and pro-caspases- 9 and -3 activation following low light dose irradiation of NPe6-sensitized 1c1c7 cells. (A) Two day-old cultures were preloaded with $66 \mu \mathrm{M} \mathrm{NPe} 6$ for $45 \mathrm{~min}$ prior to being washed, refed and irradiated $\left(67.5 \mathrm{~mJ} / \mathrm{cm}^{2}\right)$. Cultures were harvested at various times after irradiation for analyses of Bid and pro-caspase- 9 cleavage and caspase-3 activity. Parallel cultures were either not treated, or only irradiated, or only sensitized with NPe6. Symbols are means \pm S.D. of triplicate assays of a single culture and represent: no treatment $(\mathrm{X})$; irradiation alone $(\triangle)$; NPe6 alone $(\mathrm{O})$; and NPe6+irradiation $(\mathbf{O})$. (B) Cytosolic extracts were incubated in the presence of varied concentrations of NPe6 for $6 \mathrm{~h}$, or irradiated for $90 \mathrm{~s}\left(135 \mathrm{~mJ} / \mathrm{cm}^{2}\right)$, and then incubated for $6 \mathrm{~h}$ prior to being used for analyses of Bid and tBid. Parallel cultures received varying concentrations of NPe6 prior to being irradiated and incubated an additional $6 \mathrm{~h}$. Western blot analyses used $20 \mu \mathrm{g}$ of protein per lane. ECL exposure times were varied to facilitate analyses of Bid loss and tBid appearance 

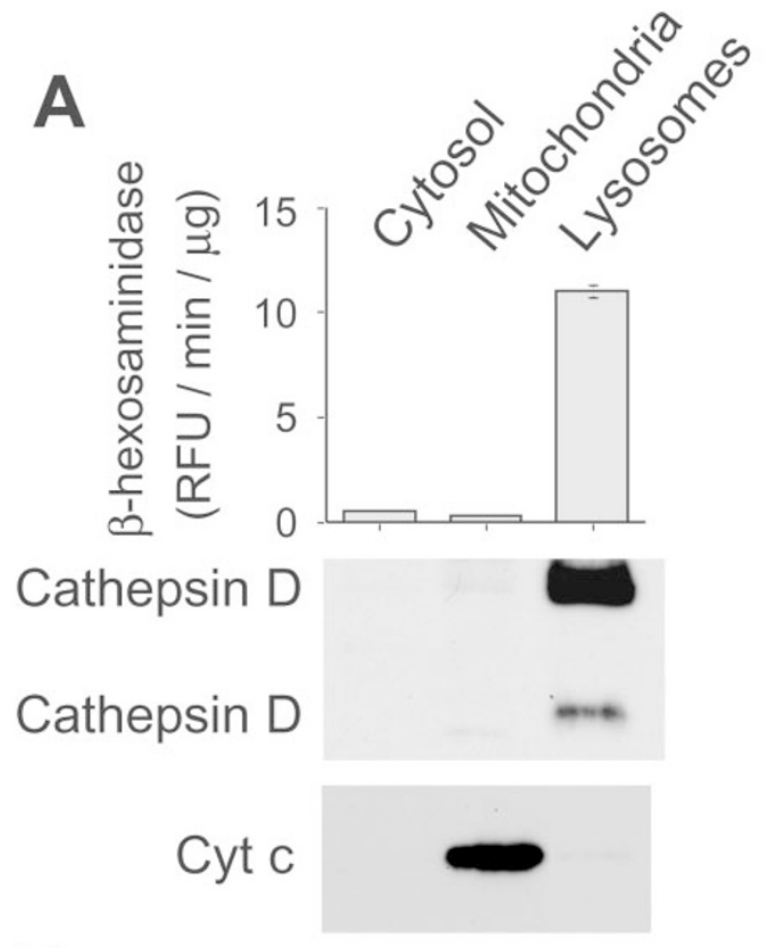

B

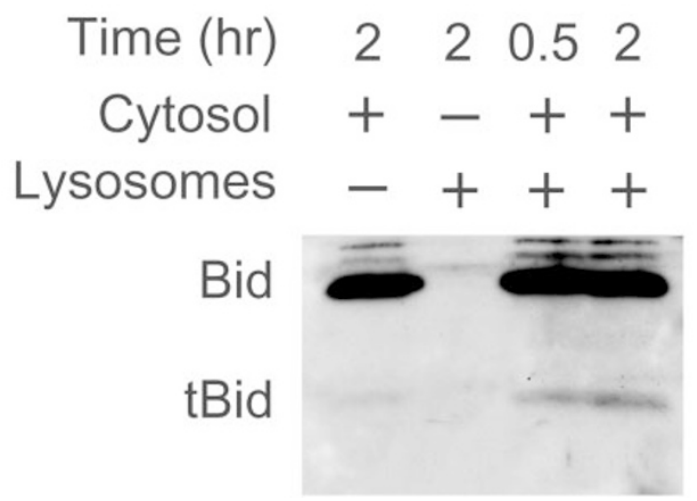

Figure 6 In vitro cleavage of Bid by lysosomal extracts. (A) Cytosol and extracts from purified lysosomes and mitochondria were assayed for $\beta$ hexosaminidase activity, and the presence of cathepsin $D$ and cytochrome $c$. Western blot analyses used $20 \mu \mathrm{g}$ of protein per lane. (B) Cytosol $(20 \mu \mathrm{g})$ and lysosomal extract $(2.5 \mu \mathrm{g})$ were mixed and incubated for either 30 or $120 \mathrm{~min}$ prior to being used in Western blot analyses. Cytosol and lysosomal extracts were incubated in parallel for $120 \mathrm{~min}$ prior to analyses. Western blot analyses in B used 20, 2.5 and $22.5 \mu \mathrm{g}$ of cytosolic, lysosomal, or cytosolic+lysosomal protein, respectively. Similar results were obtained in a second experiment employing a different preparation of lysosomes and cytosol

the absence of lysosomal extract. Hence, lysosomes isolated from 1c1c7 cells contain a protease(s) capable of either directly cleaving Bid to tBid, or activating a cytosolic protease capable of the cleavage.

Incubation of cytosol with varied amounts of lysosomal extract over the $\mathrm{pH}$ range $5.5-7.2$, for $5-30 \mathrm{~min}$, at $37^{\circ} \mathrm{C}$ did not activate cytosolic pro-caspase-3 (data not presented). However, cytosolic pro-caspase-3 could be activated by the addition of caspase-9. Addition of lysosomal extracts to cytosols containing active caspase-3 had no effects on pre-existing caspase-3 activity (data not presented). Hence, the inability of lysosomal extract to activate pro-caspase-3 did not reflect the presence of a suppressive activity.

\section{Role of cathepsin D and cysteine cathepsins in Bid cleavage and pro-caspase-3 activation}

Lysosomes/endosomes contain numerous proteolytic enzymes including the aspartic protease cathepsin $D$, and several cysteine proteases (e.g., cathepsins B and L). ${ }^{29}$ Several studies implicate a role for these lysosomal proteases in the activation of pro-caspases and the initiation and excutionary phases of apoptosis. ${ }^{30-34}$ Z-FA-FMK is a potent, irreversible inhibitor of cathepsins $B$ and $L .{ }^{35}$ We have determined that intracellular cathepsin $B$ and $L$ activities are suppressed totally within $30 \mathrm{~min}$ of exposure of $1 \mathrm{c} 1 \mathrm{c} 7$ cultures to $1 \mu \mathrm{M}$ Z-FA-FMK, and remain suppressed for at least an additional $24 \mathrm{~h} .{ }^{36}$ Co-incubation of $1 \mathrm{c} 1 \mathrm{c} 7$ cultures with $1 \mu \mathrm{M}$ Z-FA-FMK at the time of NPe6 loading altered neither the kinetics or magnitude of caspase-3 activation, nor the cleavages of Bid or pro-caspase- 9 following irradiation (Figure 7A,E).

Pepstatin $A$ is a potent inhibitor of cathepsin $D$. It is commonly used in the $50-150 \mathrm{U} / \mathrm{ml}$ range, and added to cultures $12-24 \mathrm{~h}$ prior to initiation of treatment in order to suppress cathepsin D activity. ${ }^{33,34}$ Pretreatment of $1 \mathrm{c} 1 \mathrm{c} 7$ cultures with $100 \mathrm{U} / \mathrm{ml}$ of pepstatin A for $18 \mathrm{~h}$ prior to irradiation of NPe6-sensitized cultures did not suppress pro-caspase-3 or pro-caspase-9 activation (Figure 7C,E) or Bid loss and formation of tBid (Figure 7E).

\section{Activation of pro-caspase-8 in lysosomal PDT protocols}

The fluorogenic tetrapeptide substrate Z-IETD-AFC is cleaved by caspase- 8 and granzyme $\mathrm{B}$. Either protease can cleave Bid to $\mathrm{tBid}^{37,38}$ However, we anticipated that $1 \mathrm{c} 1 \mathrm{c} 7$ cells would contain only pro-caspase- 8 because of the restricted expression of granzyme-B to immune cells. Irradiation of NPe6-sensitized 1c1c7 cultures elevated caspase-8 specific activities $\sim 5$-fold over a $6-7 \mathrm{~h}$ period (Figure 7B,D). In contrast, caspase-3 specific activities were elevated $\sim 200$-fold during the same period (Figure 7A,C). Furthermore, pro-caspase-3 activation preceded pro-caspase- 8 activation by at least $2 \mathrm{~h}$ (compare Figure $7 \mathrm{~A}$ with $\mathrm{B}$, and $C$ with D). Hence, caspase- 8 does not contribute to Bid cleavage in our PDT protocol.

\section{Discussion}

We recently reported that PDT protocols employing lysosomal photosensitizers cause an immediate disruption of the lysosomes, and a subsequent, but delayed release of cytochrome $c$ and activation of pro-caspase- $3 .^{5}$ How lysosome disruption led to cytochrome $c$ release and procaspase-3 activation was unclear. Several studies circumstantially suggest that lysosomes contain one or more 


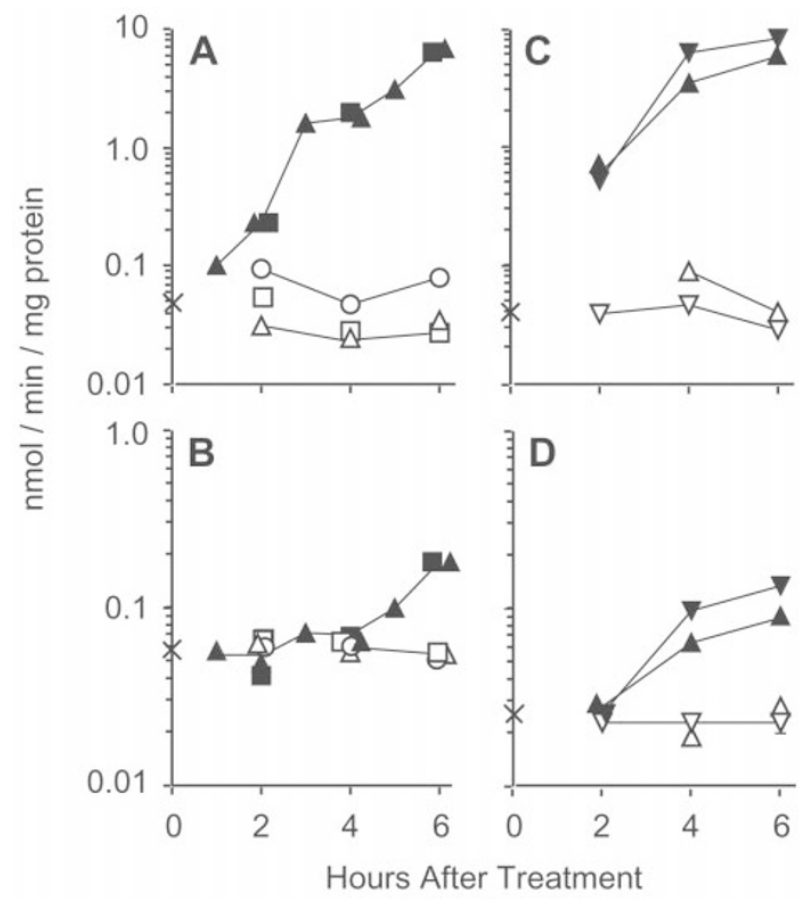

E

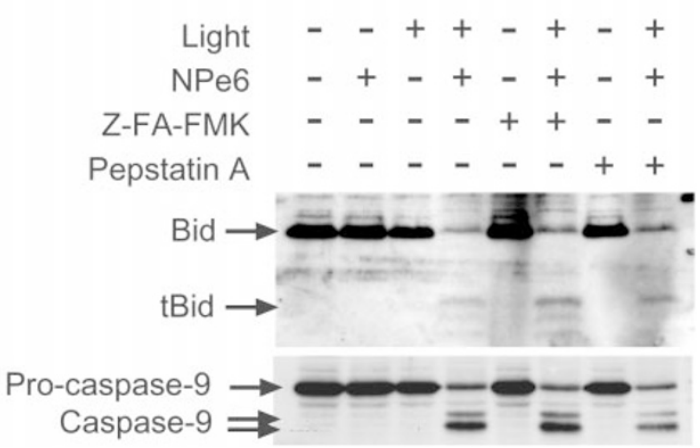

Figure 7 Effects of Z-FA-FMK and pepstatin A on NPe6/PDT-induced apoptosis. Two-day-old $1 \mathrm{c} 1 \mathrm{c} 7$ cultures were co-treated with either $1 \mu \mathrm{M}$ Z-FA FMK at the time of NPe6 loading $(\mathbf{A}, \mathbf{B}, \mathbf{E})$, or treated with pepstatin $A(100$ units $/ \mathrm{ml}) 18 \mathrm{~h}$ prior to NPe6 loading (C,D,E). Cultures were loaded with NPe6 for $45 \mathrm{~min}$ prior to being washed, refed and irradiated $\left(180 \mathrm{~mJ} / \mathrm{cm}^{2}\right)$. Cultures were subsequently harvested $1-6 \mathrm{~h}$ after irradiation for analyses of caspase-3 $(\mathbf{A}, \mathbf{C})$ and caspase-8 (B,D) activities. Other cultures were harvested $5 \mathrm{~h}$ after irradiation for Western blot analyses of Bid (E). Data in $\mathbf{A}-\mathbf{D}$ represent means \pm S.D. of triplicate assays of a single culture. Symbols are: no treatment $(X)$, light $(O)$, NPe6 $(\triangle)$, Z-FA-FMK $(\square)$, pepstatin $A(\nabla)$, NPe6+light $(\mathbf{\Delta})$, NPe6+ light+Z-FA-FMK ( $(\boldsymbol{\square})$, and NPe6+light+pepstatin A $(\boldsymbol{\nabla})$. Western blot analyses used $40 \mu \mathrm{g}$ of protein per lane. Similar results were obtained in a second independent experiment

proteases capable of directly activating pro-caspase- $3 .{ }^{13-16}$ The existence of such a protease would provide a plausible explanation for how lysosome disruption causes pro-caspase3 activation. Furthermore, Marzo et al. ${ }^{39}$ demonstrated that isolated mitochondria undergo a loss of $\Delta \Psi_{\mathrm{m}}$ and release cytochrome $c$ upon incubation with purified caspases. However, our observations are not consistent with a model entailing direct lysosomal protease activation of pro-caspase3 , and subsequent caspase-3 damage of mitochondria.
Specifically, in our NPe6 PDT protocol pro-caspase-3 activation did not occur prior to cytochrome $c$ release and pro-caspase-9 cleavage (Figure 4). Furthermore, in vitro incubation of cytosol with a lysosomal extract capable of activating Bid did not activate pro-caspase-3.

$\mathrm{Bid}$ is a pro-apoptotic member of the $\mathrm{Bcl}-2$ supergene family that is activated by limited proteolysis. ${ }^{20,21,37,38}$ The cleavage product tBid can stimulate the release of cytochrome $c$ from mitochondria. ${ }^{21,22}$ The proteolytic activation of Bid can be catalyzed by caspase-8, granzyme $B$, and an unidentified lysosomal protease..$^{19,37,38}$ Caspase8 activity was elevated following the irradiation of NPe6sensitized 1c1c7 cultures. However, the elevations (5-7fold above basal activities) were diminutive relative to caspase-3 increases ( 200-fold), and occurred after caspase-3 activation and Bid cleavage (Figure 7). Hence, it is unlikely that caspase-8 contributed to Bid cleavage in our system. Instead, a lysosomal protease is most likely responsible for Bid cleavage in our PDT model. This conclusion is based upon two findings. First, inculbation of cytosol with extracts of purified 1c1c7 lysosomes caused Bid cleavage and the formation of tBid (Figure 6). Second, PDT protocols with NPe6 caused a targeted disruption of the lysosomes. Manipulation of the PDT protocol so as to suppress lysosome disruption (e.g., exclusion of NPe6 or no irradiation) inhibited Bid cleavage. At face value, the only data casting doubt on lysosomal protease-mediated Bid cleavage in our system center on the kinetics of Bid cleavage. Specifically, although PDT caused a rapid disruption of the lysosomes, tBid was not observed until 2 or $3 \mathrm{~h}$ post irradiation. There are two possible explanations for the delayed kinetics of Bid cleavage. First, a variety of lysosomal protease inhibitors are normally present in the cytoplasm. ${ }^{29,40}$ The enzymatic activity responsible for Bid cleavage may be suppressed by these inhibitors. In essence, the delayed kinetics may simply represent limited availability of active protease. Alternatively, Desagher et al. ${ }^{41}$ reported recently that Bid is a phosphoprotein, and that the phosphorylated form is resistant to caspase-8mediated in vitro cleavage. Furthermore, in vivo studies comparing Fas-induced cleavage of wild-type phosphorylated and mutant non-phosphorylated Bid in engineered cell lines showed that phosphorylation delayed caspase-8mediated Bid cleavage by at least $1 \mathrm{~h} .{ }^{41}$ We are currently attempting to determine whether the delayed Bid cleavage seen in out PDT protocols reflects either of the above two situations.

The identity of the lysosomal protease(s) responsible for Bid cleavage is not known. Pharmacological inhibitors of cathepsins $B, D$ and $L$ have implicated initiating and executionary roles for these lysosomal proteases in several apoptotic models. ${ }^{33,34}$ However, pharmacological inhibition of these three proteases did not suppress Bid cleavage or pro-caspase-3 activation in our PDT model. Lysosomes/ endosomes contain several cysteine proteases besides cathepsins B and L. ${ }^{29}$ Stoka et al. ${ }^{19}$ recently reported that in vitro supplementation of lysosomal extracts with the broad spectrum cysteine protease inhibitor E64 also failed to inhibit Bid cleavage. Hence, it is unlikely that lysosomal cysteine proteases are involved in Bid cleavage. We have 
identified cell lines which lack the protease responsible for Bid cleavage, and do not undergo apoptosis following PDT with NPe6 (Reiners and Caruso, unpublished data). These lines should aid in the identification of the Bid-cleaving protease.

In our PDT protocol the appearance of tBid preceded/ coincided with the release of cytochrome $c$ and the activations of pro-caspases- 9 and -3 . Furthermore, cytochrome $c$ release/caspase-9 and -3 activation occurred prior to the loss of $\Delta \Psi_{\mathrm{m}}$. These properties are characteristic of tBid-mediated cytochrome $c$ release. ${ }^{22-24}$ We hypothesize that PDT protocols employing lysosomal sensitizers initiate apoptosis by disrupting lysosomes and releasing one or more proteases into the cytosol which are involved in the conversion of Bid to tBid. In turn, tBid triggers the release of cytochrome $c$ which stimulates the activation of pro-caspase-3 via activation of Apaf-1/pro-caspase-9. In essence, the generation of tBid by lysosomal enzymes provides a mechanism for how lysosomal disruption can trigger apoptosis via the cytochrome c/Apaf-1/caspase-9 pathway.

Our studies raise two related issues. First, how common is lysosome disruption? Second, how often is cytochrome $c$ release and activation of the Apaf-1/caspase- 9 pathway actually initiated by lysosome disruption? We do not have the answers to these questions. However, a variety of cytotoxic agents cause lysosomal damage. For example, lysosomal disruption and release of lysosomal proteases into the cytoplasm occurs during alpha-tocopheryl succinate-induced apoptosis in Jurkat T cells, ${ }^{42}$ during serumwithdrawal-induced apoptosis in PC12 cells, ${ }^{30}$ during naphthazarine-induced apoptosis of neonatal cardiomyocytes $^{31}$ and foreskin fibroblasts, ${ }^{32}$ and following exposure of macrophages to O-methyl-serine dodecylamide hydrochloride. ${ }^{43}$ In at least three of these studies lysosomal damage occurred prior to the release of cytochrome $c$ and/ or loss of $\Delta \Psi_{\mathrm{m}} \cdot{ }^{32,42,43}$ Two groups have also reported that $\mathrm{H}_{2} \mathrm{O}_{2}$ causes lysosome disruption and the induction of apoptosis, necrosis, or both. ${ }^{44,45}$ The mode of death appears to be dependent upon the concentration of $\mathrm{H}_{2} \mathrm{O}_{2}$ used to treat the cells. ${ }^{44}$ In $\mathrm{H}_{2} \mathrm{O}_{2}$-induced apoptosis, lysosome disruption occurred quickly ${ }^{44}$ and preceded cytochrome $c$ release and loss of $\Delta \Psi_{\mathrm{m}}{ }^{45}$ A recent study by Nilsson et al. ${ }^{46}$ is particularly germane to the questions raised above. Specifically, these investigators demonstrated that lysosomal membranes are very susceptible to damage and disruption by a variety of oxidants. Similar findings have been reported by Brunk and Svensson. ${ }^{47}$ It should be noted that oxidants are the cytotoxic species generated in PDT protocols and with naphthazarine. These latter papers, in conjunction with the current study, raise the issue of whether oxidant-induced cytochrome $c$ release and Apaf-1/pro-caspase- 9 activation are actually the downstream consequences of lysosomal damage. This is a question that we are actively pursuing.

A distinct advantage of the PDT model used in the current study is the specificity with which one can damage lysosomes. The studies reported in Figure 1 clearly indicate that NPe6 preferentially accumulates in a subpopulation of $1 \mathrm{c1c7}$ organelles stained with LTB. An electron microscopy study has also shown that lysosomes are specifically destroyed in NPe6 sensitized, irradiated cells. ${ }^{10}$ Although Stoka et al. ${ }^{19}$ have shown that a lysosomal extract can activate Bid in vitro, the current investigation is the first we know of to: (1) demonstrate that targeted lysosome disruption in vivo is associated with Bid cleavage, and (2) provide a mechanistic basis for how lysosomal sensitizers in PDT protocols cause cytochrome $c$ release and procaspases-9/-3 activation. Given the susceptibility of lysosomes to oxidant-induced injury, it is conceivable that lysosomal disruption may be a relatively common initiator of the mitochondrial/intrinsic apoptotic pathway.

\section{Materials and Methods}

\section{Chemicals}

NPe6 was provided by Dr. Kevin M Smith, Department of Chemistry, University of California at Davis. Fluorescent probes for mitochondrial membrane potential (TMRM), lysosomal integrity (AO or LTB), and chromatin condensation (HO342) were purchased from Molecular Probes (Eugene, OR, USA). AC-DEVD-AMC and Ac-IETD-AFC were purchased from BD Transduction Laboratories (San Diego, CA, USA). 4-Methylumbelliferyl $\mathrm{N}$-acetyl- $\beta$-D-glucosaminide was purchased from Sigma (St. Louis, MO, USA). Z-FA-FMK was obtained from Enzyme Systems Products (Livermore, CA, USA). Pepstatin A, AMC and AFC were purchased from Calbiochem (La Jolla, CA, USA).

\section{Cell culture}

Murine hepatoma Hepa 1c1c7 cells were obtained from Dr. JP Whitlock Jr, Stanford University, CA, USA. They were grown in $\alpha$-MEM supplemented with $5 \%$ fetal calf serum and antibiotics in a $5 \% \mathrm{CO}_{2}$ atmosphere, at $37^{\circ} \mathrm{C}$, in either culture dishes or on $12 \mathrm{~mm}$ glass coverslips coated with poly-L-lysine.

\section{Fluorescent detection of NPe6}

Subconfluent monolayers of 1c1c7 cells grown on coverslips were preloaded with NPe6 for $\sim 30 \mathrm{~min}$. After loading the coverslips were washed $3 \times$ with PBS and transferred to culture dishes containing fresh medium and $50 \mathrm{nM} \mathrm{LTB}$. After a $10 \mathrm{~min}$ incubation at $37^{\circ} \mathrm{C}$ in a humidified $5 \% \mathrm{CO}_{2}$ chamber, the coverslips were washed $3 \times$ with PBS and viewed with a Nikon E600 fluorescence microscope equipped with a Photometrics SenSys CCD camera (Roper Scientific, Trenton, NJ, USA) cooled to $-40^{\circ} \mathrm{C}$. NPe6 fluorescence was acquired first and was detected using 400-440 nm excitation and 650-700 nm emission. The wavelengths for acquiring LTB fluorescence in the same cultures were 400-440 nm excitation and 450-500 nm emission. After image capture, MetaMorph software (Universal Imaging Corp. Westchester, PA, USA) was used to assign red for NPe6 fluorescence, and green for LTB fluorescence, so that colocalized fluorescent molecules yielded orange/yellow fluorescence.

\section{PDT protocols}

Subconfluent monolayers of $2-3$ day old cultures were preloaded with $\mathrm{NPe} 6$ for $\sim 45 \mathrm{~min}$. After loading the cultures were washed $3 \times$ with PBS, refed and then irradiated. Cultures loaded with NPe6 were irradiated for varying lengths of time at $22^{\circ} \mathrm{C}$ using a $600 \mathrm{~W}$ quartzhalogen lamp with IR radiation attenuated by a $10 \mathrm{~cm}$ layer of water 
and $850 \mathrm{~nm}$ cutoff filter. The bandwidth was further confined to $650-$ $700 \mathrm{~nm}$ by a broadband interference filter. Light intensity was $1.5 \mathrm{~mW} /$ $\mathrm{cm}^{2}$. Hence, $1 \mathrm{~s}$ of irradiation $=1.5 \mathrm{~mJ} / \mathrm{cm}^{2}$.

\section{Fluorescence microscopy of mitochondria, lysosomes and nuclei}

Apoptotic nuclear morphology was assessed by labeling adherent cells for $10 \mathrm{~min}$ at $37^{\circ} \mathrm{C}$ with $\mathrm{HO} 342(5 \mu \mathrm{M})$. Cultures were then washed $3 \times$ with PBS and observed by fluorescence microscopy using $330-380 \mathrm{~nm}$ excitation and measuring fluorescence at $420-450 \mathrm{~nm}$. The same cultures were simultaneously loaded with either $0.5 \mu \mathrm{M} \mathrm{AO}$ or $5 \mu \mathrm{M}$ TMRM in order to image lysosomes or $\Delta \Psi_{\mathrm{m}}$, respectively. The wavelengths for acquiring $A O$ fluorescence were $400-440 \mathrm{~nm}$ excitation and $590-650 \mathrm{~nm}$ emission. An exposure time of $0.1 \mathrm{~s}$ was used to acquire $A O$ fluorescence, and was insufficient to cause AO-mediated lysosome disruption. The wavelengths for acquiring TMRM fluorescence were $510-560 \mathrm{~nm}$ excitation and $590-650 \mathrm{~nm}$ emission.

\section{Effects of PDT on cell viability}

Subconfluent cultures were trypsinized, washed and subsequently suspended in culture medium and plated. NPe6 was added $\sim 16-$ $18 \mathrm{~h}$ after plating. After $\sim 45 \mathrm{~min}$ the cultures were washed $3 \times$ with PBS, and refed immediately prior to irradiation. After irradiation cultures were returned to a humidified $5 \% \mathrm{CO}_{2}$ chamber and incubated at $37^{\circ} \mathrm{C}$. The medium was changed every 3 days and colonies were scored 8-10 days after plating. Previous studies have shown that only a low percentage of Hepa 1c1c7 cells divide in the first $20 \mathrm{~h}$ after passaging, and that this time is sufficient to replenish the glutathione lost from the cells as a consequence of trypsinization. ${ }^{48}$

\section{Caspases- 3 and -8 assays}

Cultures were washed twice with PBS before being flooded with lysis buffer (10 mM Tris, pH 7.5, $130 \mathrm{mM} \mathrm{NaCl}, 1 \%$ Triton X-100, $10 \mathrm{mM}$ $\mathrm{NaF}, 10 \mathrm{mM}$ sodium phosphate, and $10 \mathrm{mM}$ sodium pyrophosphate). Cells in culture medium and PBS washes were pooled, washed with PBS, and pelleted by centrifugation. After $\sim 3-10$ min of incubation on ice, culture dishes were scraped and the lysate was added to the cell pellet derived from the culture medium. The lysate was then transferred to a small tube, sonicated for $1 \mathrm{~s}$, and centrifuged at $13000 \times g$ for $5 \mathrm{~min}$. Supernatant fluids were aliquotted and stored at $-80^{\circ} \mathrm{C}$. The procedure for assay of caspase- 3 using Ac-DEVD-AMC as substrate has been described in detail. ${ }^{49}$ Assays for caspase-8/ granzyme B activities used Z-IETD-AFC as the substrate and monitored the release of AFC using excitation and emission wavelengths of 400 and $505 \mathrm{~nm}$, respectively. The assay mixture contained $100 \mathrm{mM}$ HEPES ( $\mathrm{pH} 7.5$ ), 10\% sucrose, $2 \mathrm{mM}$ DTT, $0.5 \mathrm{mM}$ EDTA and $20 \mu \mathrm{M}$ Z-IETD-AFC. The assay was initiated by the addition of cell lysate. Release of AMC and AFC was monitored at $37^{\circ} \mathrm{C}$ with a fluorescence plate reader. Changes in fluorescence over time were converted into pmol of product by comparison to standard curves made with AMC or AFC. Caspases- 3 and -8 specific activities are reported as $\mathrm{nmol}$ product $/ \mathrm{min} / \mathrm{mg}$ protein. The Bio-Rad Protein assay, using BSA as a standard, was used to estimate protein concentrations.

\section{$\beta$-Hexosaminidase assay}

The assay described by Storrie and Madden ${ }^{50}$ was modified slightly and used to assay $\beta$-hexosaminidase. Assays were performed in
$200 \mu \mathrm{l}$ reaction volumes and contained $100 \mu \mathrm{M}$ sodium acetate buffer (pH 4.4), extract, and the substrate $1 \mathrm{mM}$ 4-methylumbelliferyl $\mathrm{N}$ acetyl- $\beta$-D-glucosaminide. Reactions were initiated by the addition of substrate. Substrate cleavage was monitored with a SPECTRAmax Gemini Dual-Scanning Microplate Spectrofluorometer using excitation and emission wavelengths of 364 and $448 \mathrm{~nm}$, respectively. $\beta$ Hexosaminidase activity is reported as relative fluorescence units $(\mathrm{RFU}) / \mathrm{min} / \mu \mathrm{g}$ protein.

\section{Preparation of cytosol for Bid cleavage assays}

Cells were released from culture dishes with trypsin/EDTA, mixed with $\alpha \mathrm{MEM}$ plus $5 \% \mathrm{FBS}$, and pelleted by centrifugation. The pellet $\left(\sim 10^{8}\right.$ cells) was resuspended in PBS. The cell suspension was pelleted by centrifugation and resuspended in $0.25 \mathrm{M}$ sucrose. After an additional washing with $0.25 \mathrm{M}$ sucrose the cell pellet was resuspended in $1 \mathrm{ml}$ of $0.25 \mathrm{M}$ sucrose and homogenized with a dounce tissue grinder (Wheaton \#357538) using 15 strokes. The resulting homogenate was sequentially centrifuged at $14000 \times g$ for 5 min and $100000 \times g$ for $1 \mathrm{~h}$. The supernatant fluid represented 'cytosol' and was aliquotted and stored at $-80^{\circ} \mathrm{C}$.

\section{Preparation of lysosomes and mitochondria}

The procedure described by Storrie and Madden ${ }^{50}$ was modified in order to purify lysosomes and mitochondria from $1 \mathrm{c} 1 \mathrm{c} 7$ cells. Cultures ( $20 \times 100 \mathrm{~mm}$ culture dishes) were washed twice with PBS and once with $0.25 \mathrm{M}$ sucrose before the addition of $200 \mu \mathrm{l} / 100 \mathrm{~mm}$ culture dish of $0.25 \mathrm{M}$ sucrose. The cells were scraped from the plates, combined and homogenized with a motor-driven teflon pestle and plastic-coated tissue grinder (Wheaton \#358005) using 4 strokes. The homogenate was centrifuged at $1300 \times g$ for $5 \mathrm{~min}$. The pellet was resuspended in $1 \mathrm{ml}$ of $0.25 \mathrm{M}$ sucrose, and recentrifuged as before. The combined supernatant fluids were layered on a density gradient consisting of $35 \%$ metrizamide, $17 \%$ metrizamide, 6\% Percoll (all dilutions were made in $0.25 \mathrm{M}$ sucrose) and centrifuged at $56000 \times \mathrm{g}$ for $15 \mathrm{~min}$. To isolate lysosomes $800 \mu \mathrm{l}$ of the Percoll $/ 17 \%$ metrizamide interface was removed and combined with $800 \mu \mathrm{l}$ of $70 \%$ metrizamide and overlayed with $17 \%$ metrizamide, $5 \%$ metrizamide and $0.25 \mathrm{M}$ sucrose. This gradient was centrifuged as before. Lysosomes banding at the $5 \% /$ $17 \%$ metrizamide interface and mitochondria banding at the $17 \% / 35 \%$ interface of the first density gradient, were diluted to $24 \mathrm{ml}$ with $0.25 \mathrm{M}$ sucrose and centrifuged at $56000 \times g$ for $20 \mathrm{~min}$. The lysosomal and mitochondrial pellets were resuspended in lysis buffer (see caspase assays), sonicated for $1 \mathrm{~s}$, and centrifuged at $14000 \times g$ for $10 \mathrm{~min}$. Supernatant fluids were aliquotted and stored at $-80^{\circ} \mathrm{C}$.

\section{In vitro Bid cleavage assay}

Cytosol $(20 \mu \mathrm{g})$ was incubated with or without $2.5 \mu \mathrm{g}$ of lysosomal extract for either 30 or $120 \mathrm{~min}$ at $37^{\circ} \mathrm{C}$ in a $30 \mu$ reaction mixture containing $100 \mu \mathrm{M}$ sodium acetate, $\mathrm{pH}$ 5.5. Reactions were terminated by the addition of SDS-PAGE loading buffer.

\section{Western blot analyses}

A procedure described by Fan et al. ${ }^{51}$ was used to analyze for mitochondrial cytochrome $c$ release. Cultures were released by trypsin/EDTA treatment and pelleted by centrifugation. The pellets were washed once with ice-cold PBS and resuspended in five volumes of homogenization buffer (20 mM HEPES, pH 7.5, $10 \mathrm{mM} \mathrm{KCl}, 1.5 \mathrm{mM}$ $\mathrm{MgCl}_{2}, 1 \mathrm{mM}$ EDTA, $1 \mathrm{mM}$ EGTA, $1 \mathrm{mM}$ dithiothreitol, $0.1 \mathrm{mM}$ phenylmethylsulfonyl fluoride and $250 \mathrm{mM}$ sucrose). After incubation 
on ice for $15 \mathrm{~min}$ the cell suspensions were homogenized with 15 strokes of a tightly fitting, non ground glass Wheaton Dounce homogenizer. The homogenate was successively centrifuged at $750 \times g$ for $10 \mathrm{~min}, 10000 \times g$ for $15 \mathrm{~min}$, and then $100000 \times g$ for $1 \mathrm{~h}$. All centrifugations were performed at $4^{\circ} \mathrm{C}$. The $10000 \times g$ pellet was used as a source of mitochondria. The $100000 \times g$ supernatant fluid represented the cytosolic fraction. Mitochondrial pellets and supernatant fluids were frozen and stored at $-80^{\circ} \mathrm{C}$ until used.

Polypeptides in cytosolic supernatant fluids, or extracts from purified mitochondria or lysosomes, were separated on $12.5 \%$ (for caspase- 9 and cathepsin D) or $15 \%$ (for Bid and cytochrome c) polyacrylamide-SDS gels, and electrophoretically transferred onto nitrocellulose. After transfer the blots were incubated with blocking solution (5\% Carnation dehydrated nonfat milk in PBS/0.1\% Tween 20) overnight at $4{ }^{\circ} \mathrm{C}$. Blocked blots were washed with $\mathrm{PBS} / 0.1 \%$ Tween 20 and subsequently incubated overnight at room temperature with a monoclonal antibody made to pigeon cytochrome $c$ (PharMingen, San Diego, CA, USA), or a rabbit polyclonal antibody made to murine caspase-9 (product \#9504; Cell Signaling Technology, Beverly, MA, USA), or a rabbit polyclonal antibody made to recombinant DNA-derived murine $\mathrm{Bid}^{21}$ or a rabbit polyclonal antibody made to human Cathepsin D (product Im16, Oncogene Research Products, Boston, MA, USA). All antibodies were diluted in PBS, $0.1 \%$ Tween-20, 5\% BSA. Primary murine antibodies were detected with sheep anti-mouse IgG conjugated with horseradish peroxidase (Amersham Pharmacia Biotech, Inc., Piscataway, NJ, USA). Primary rabbit antibodies were detected with horseradish peroxidase-linked donkey anti-rabbit IgG (Amersham Pharmacia Biotech, Inc.). Immune complexes were visualized with an ECL detection kit (Amersham Pharmacia Biotech, Inc.) and recorded on X-ray film.

\section{Acknowledgements}

This work was supported by NIEHS grant ES09392 and NIH grant CA23378, and was assisted by the services of the Cell Culture Core and the Cell Imaging and Cytometry Core, which are supported by NIEHS grant P30 ES06639.

\section{References}

1. Dougherty TJ, Gomer CJ, Henderson BW, Jori G, Kessel D, Korbelik M, Moan J and Peng Q (1998) Photodynamic therapy. J. Natl. Cancer Inst. 90: 889-905

2. Agarwal ML, Clay ME, Harvey EJ, Evans HH, Antunex AR and OleinickNL (1991) Photodynamic therapy induces rapid cell death by apoptosis in L5178Y mouse lymphoma cells. Cancer Res. 51:5993-5996

3. Oleinick NL, Morris RL and Belichenko I (2002) Apoptosis in response to photodynamic therapy: what, where, why and how. Photochem. Photobiol. Sci. 1: $1-21$

4. Noodt BB, Berg K, Stokke Q, Peng Q and Nesland JM (1999) Different apoptotic pathways are induced from various intracellular sites by tetraphenylporphyrins and light. Br. J. Cancer 79: 72-81

5. Kessel D, Luo Y, Mathieu P and Reiners Jr JJ (2000) Determinants of the apoptotic response to lysosomal photodamage. Photochem. Photobiol. 71 : $196-200$

6. Woodburn KW, Fan Q, Miles DR, Kessel D, Luo Y and Young SW (1997) Localization and efficacy analysis of the phototherapeutic lutetium texaphyrin (PCl-0123) in the murine EMT6 sarcoma model. Photochem. Photobiol. 65: $410-415$

7. Kessel D, Caruso JA and Reiners Jr JJ (2000) Potentiation of photodynamic therapy by ursodeoxycholic acid. Cancer Res. 60: 6985-6988

8. Kessel D, Luo Y, Deng Y and Chang CK (1997) The role of sub-cellular localization in initiation of apoptosis by photodynamic therapy. Photochem. Photobiol. 65: 422-426
9. Chiu SM and Oleinick NL (2001) Dissociation of mitochondrial depolarization from cytochrome $\mathrm{c}$ release during apoptosis induced by photodynamic therapy. Br. J. Cancer 84: 1099-1106

10. Roberts WG, Liaw LH and Berns MW (1989) In vitro photosensitization II. An electron microscopy study of cellular destruction with mono-L-aspartyl chlorin e6 and photofrin II. Lasers Surg. Med. 9: 102-108

11. Trivedi NS, Wang HW, Nieminen AL, OleinickNL and IzattJA (2000) Quantitative analysis of Pc 4 localization in mouse lymphoma (LY-R) cells via double-label confocal fluorescence microscopy. Photochem. Photobiol. 71: 634-639

12. Moan $\mathrm{J}$ and Berg K (1991) The photodegradation of porphyrins in cells can be used to estimate the lifetime of singlet oxygen. Photochem. Photobiol. 53: 549553

13. Kessel D and Castelli $M$ (2001) Evidence that bcl-2 is the target of three photosensitizers that induce a rapid apoptotic response. Photochem. Photobiol. 74: $318-322$

14. Xue LY, Chiu SM and Oleinick NL (2001) Photochemical destruction of the Bcl-2 oncoprotein during photodynamic therapy with the phthalocyanine photosensitizer Pc 4. Oncogene 20: 3420-3427

15. Ishisaka R, Utsumi T, Yabuki M, Kanno T, Furuno T, Inoue Mand UtsumiK(1998) Activation of caspase-3-like protease by digitonin-treated lysosomes. FEBS Lett. 435: 233-236

16. Ishisaka R, Utsumi T, Kanno T, Arita K, Katunuma N, Akiyama J and Utsumi K (1999) Participation of a cathepsin L-type protease in the activation of caspase-3. Cell Struct. Funct. 24: 465-470

17. Ishisaka R, Kanno T, Akiyama J, Yoshioka T, Utsumi K and Utsumi T (2001) Activation of caspase-3 by lysosomal cysteine proteases and its role in $2,2^{\prime}$ azobis-(2-amidinopropane)-dihydrochloride (AAPH)-induced apoptosis in $\mathrm{HL}$ 60 cells. J. Biochem. (Tokyo) 129: 35-41

18. Hishita T, Tada-Oikawa S, Tohyama K, Miura Y, Nishihara T, Tohyama Y, Yoshida Y, Uchiyama T and Kawanishi S (2001) Caspase-3 activation by lysosomal enzymes in cytochrome c-independent apoptosis in myelodysplastic syndrome-derived cell line P39. Cancer Res. 61: 2878-2884

19. Stoka V, Turk B, Schendel S L, Kim T-H, Cirman T, Snipas SJ, Ellerby LM, Bredesen D, Freeze H, Abrahamson M, Brömmer D, Krajewski S, Reed JC, Yin X-M, Turk V and Salvesen GS (2001) Lysosomal protease pathways to apoptosis: cleavage of Bid, not pro-caspases, is the most likely route. J. Biol. Chem. 276: 3149-3157

20. Adams JM and Cory S (1998) The Bcl-2 protein family: arbiters of cell survival. Science 281: $1322-1326$

21. Wang K, Yin X-M, Chao DT, Milliman CL and Korsmeyer SJ (1996) BID: a novel $\mathrm{BH} 3$ domain-only death agonist. Genes Dev. 10: 2859-2869

22. Shimizu S and Tsujimoto Y (2000) Proapoptotic BH3-only Bcl-2 family members induce cytochrome $c$ release, but not mitochondrial membrane potential loss, and do not directly modulate voltage-dependent anion channel activity. Proc. Natl. Acad. Sci. USA 97: 577-582

23. Zhai D, Huang X, Han X and Yang F (2000) Characterization of tBid-induced cytochrome $c$ release from mitochondria and liposomes. FEBS Lett. 472: $293-$ 296

24. Kim TH, Zhao Y, Barber MJ, Kuharsky DK and Yin X-M (2000) Bid-induced cytochrome $c$ release is mediated by a pathway independent of mitochondrial permeability transition pore and Bax. J. Biol. Chem. 275: 39474-39481

25. Korsmeyer SJ, Wei MC, Saito M, Weiler S, Oh KJ and SchlesingerPH(2000) Proapoptotic cascade activated BID, which oligomerizes BAK or BAX into pores that result in the release of cytochrome c. Cell Death Differ. 7: 1166-1173

26. Wei MC, Lindsten T, Nootha VK, Weiler S, Gross A, Ashiya M, Thompson CB and Korsmeyer SJ (2000) tBid, a membrane-targeted death ligand, oligomerizes BAK to release cytochrome c. Genes Dev. 14: 2060-2071

27. Nechushtan A, Smith, CL, LamensdorfI, Yoon SH and Youle RJ (2001) Bax and Bak coalesce into novel mitochondria-associated clusters during apoptosis. J. Cell Biol. 153: 1265-1276

28. Peng Q, Farrants GW, Madslien K, Bommer JC, Moan J, Danielsen HE and Nesland JM (1991) Subcellular localization, redistribution and photobleaching of sulfonated aluminum phthalocyanines in a human melanoma cell line. Int. J. Cancer 49, 290-295

29. Sloane, BF, Moin K and Lah TT (1994) Regulation of lysosomal endopeptidases in malignant neoplasia. In Biochemical and Molecular Aspects of Selected Cancers, Vol. 2, Pretlow II TG and Pretlow TP, eds (London, Academic Press) pp 411-466 
30. Ohsawa Y, Isahara K, Kanamori S, Shibata M, Kametaka S, Gotow T, Watanabe T, Kominami E and Uchiyama Y (1998) An ultrastructural and immunohistochemical study of $\mathrm{PC} 12$ cells during apoptosis induced by serum deprivation with special reference to autophagy and lysosomal cathepsins. Arch. Histol Cytol. 61 395-403

31. Roberg K and Öllinger K (1998) Oxidative stress causes relocation of the lysosomal enzyme cathepsin $D$ with ensuing apoptosis in neonatal rat cardiomyocytes. Amer. J. Path. 152: 1151-1156

32. Roberg K, Johansson U and Öllinger K (1999) Lysosomal release of cathepsin D precedes relocation of cytochrome $c$ and loss of mitochondrial transmembrane potential during apoptosis induced by oxidative stress. Free Rad. Biol. Med. 27: $1228-1237$

33. Öllinger K (2000) Inhibition of cathepsin D prevents free-radical-induced apoptosis in rat cardiomyocytes. Arch. Biochem. Biophys. 373: 346-351

34. Isahara K, Ohsawa Y, Kanamori S, Shibata M, Waguri S, Gotwo T, Watanabe T, Momoi T, Urase K, Kominami E and Uchiyama Y (1999) Regulation of a novel pathway for cell death by lysosomal aspartic and cyteine proteinases. Neuroscience 91: 233-249

35. Rasnick D (1985) Synthesis of peptide fluoromethylketones and the inhibition of human cathepsin B. Anal. Biochem. 149: 461-465

36. Guo M, Mathieu PA, Linebaugh B, Sloane BF and Reiners Jr JJ (2002) Phorbo ester activation of a proteolytic cascade capable of activating latent TGF- $\beta$ : A process initiated by the exocytosis of cathepsin B. J. Biol. Chem. 277: 1482914837

37. Luo X, Budihardjo I, Zou H, Slaughter C, and Wang X (1998) Bid, a Bcl-2 interacting protein, mediates cytochrome $\mathrm{c}$ release from mitochondria in response to activation of cell surface death receptors. Cell 94: 481-490

38. Li H, Xu C-J and Yuan J (1998) Cleavage of BID by caspase 8 mediates the mitochondrial damage in the Fas pathway of apoptosis. Cell 94: 491-501

39. Marzo I, Susin SA, Petit PX, Ravagnan L, Brenner C, Larochette N, Zamzami N and Kroemer G (1998) Caspases disrupt mitochondrial membrane barrier function. FEBS Lett. 427: 198-202

40. Shridhar R, Sloane BF and Keppler D (2000) Inhibitors of papain-like cysteine peptidases. In Handbook of Experimental Pharmacology vol 140, von der Helm K, Korant BD and Cheronis JC, eds (Berlin: Springer-Verlag) pp. 301-328
41. Desagher S, Osen-Sand A, Montessuit S, Magnenat E, Vilbois F, Hochmann A, Journot L, Antonsson B and Martinou JC (2001) Phosphorylation of Bid by casein kinases I and II regulates its cleavage by caspase 8 . Mol. Cell 8: 601-611

42. Neuzil J, Svensson I, Weber T, Weber C and Brunk UT (1999) Alpha-tocopheryl succinate-induced apoptosis in Jurkat T cells involves caspase-3 activation, and both lysosomal and mitochondrial destabilization. FEBS Lett. 445: 295-300

43. LiW, Yuan X, Nordgren G, Dalen H, Dubowchik GM, Firestone RA and Brunk UT (2000) Induction of cell death by the lysosomotropic detergent MSDH. FEBS Lett. 470: $35-39$

44. Antunes F, Cadenas E and BrunkUT (2001) Apoptosis induced by exposure to a low steady-state concentration of hydrogen peroxide is a consequence of lysosomal rupture. Biochem. J. 356: 549-555

45. Dare E, Li W, Zhivotovsky B, Yuan X and Ceccatelli S (2001) Methylmercury and hydrogen peroxide provoke lysosomal damage in human astrocytoma D384 cells followed by apoptosis. Free Rad. Biol. Med. 30: 1347-1356

46. Nilsson E, Ghassemifar R and Brunk UT (1997) Lysosomal heterogeneity between and within cells with respect to resistance against oxidative stress. Histochem. J. 29: 857-863

47. Brunk UT and Svensson I (1999) Oxidative stress, growth factor starvation and Fas activation may all cause apoptosis through lysosomal leak. Redox Rep. 4: $3-11$

48. Reiners Jr JJ, Mathieu P, Okafor C, Putt DA and Lash LH (2000) Depletion of cellular glutathione by conditions used for the passaging of adherent cultured cells. Toxicol. Lett. 115: 153-163

49. Reiners Jr JJ and Clift RE (1999) Aryl hydrocarbon receptor regulation of ceramide-induced apoptosis in murine hepatoma 1c1c7 cells. A function independent of aryl hydrocarbon receptor nuclear translocator. J. Biol. Chem. 274: $2502-2510$

50. Storrie B and Madden EA (1990) Isolation of subcellular organelles. Meth. Enzymol. 182: 203-222

51. Fan T, Lu H, Hu H, Shi L, McClarty GA, Nance DM, Greenberg AH and Zhong G (1998) Inhibition of apoptosis in chlamydia-infected cells: blockade of mitochondrial cytochrome c release and caspase activation. J. Exp. Med. 187: 487-496 